\title{
Perspective of Jute in a New Realm beyond Sacking
}

\author{
Deb Prasad Ray** and Rakesh Kumar Ghosh
}

ICAR-National Institute of Natural Fibre Engineering and Technology, 12 Regent Park, Kolkata- 700040, West Bengal, India

*Corresponding author: drdebprasadray@gmail.com

\begin{abstract}
Jute is an eco-friendly, cheap and excellent fibre, traditionally used for sacking and hessian. India produces $80 \%$ of jute of total global demand. Owing to environment friendly properties, this 'golden fiber' has been used as a safe material for packing and transport. However, dilution of JPM act coupled with competition from synthetic/ man-made fibres, demand of jute for traditional usages i.e. sacking and hessian has decreased over past five years. Under such circumstances, application of jute for diversified product has become necessary for survival of around 44 lakhs direct and indirectly related workers (covering farmers and mill workers) associated with the jute industry. Jute diversified products like shopping bags, wall hangings, floor covering, non-ovens, geo-textiles, composites etc has opened up a new realm beyond traditional application of jute. Export of jute diversified products has increased from INR 363.593 to 590.215 corers during 2012-13 to 2016-17. Present status paper reports various type of jute diversified products along with their market scope, performance and opportunity across the world.
\end{abstract}

Keywords: Jute, traditional uses, diversification, export, market opportunity

The 'golden fibre' of jute (Corchorus olitorius $\mathcal{E} C$. capsularis) is one of the most important naturalfibre after cotton. Thisbastfibre, jute, possess all qualities for a 'safe' packing material because of its natural, biodegradable, renewable and environment friendly nature (Ray et al. 2015a; Bag et al. 2016; Ray et al. 2016; Kumar, 2017). For past few decades jute fibre has been used as a carrier material during transport of food grains and materials. Jute cultivation is mainly concentrated in South-East Asian countries namely India, Bangladesh, China, Nepal, Bhutan, Thailand etc. However, more than $80 \%$ of the total global demand is supplied by India, followed by Bangladesh (Bag et al. 2016). In India, the jute cultivation for the 'golden fibre' is practiced in East and North-eastern states namely, West Bengal, Bihar, Orissa, Assam, Meghalaya and Tripura. With the help of modern technologies and proper agricultural inputs coupled with good agricultural practices, the jute production has increased from 16.7 lakh bales (in 1947-48) to nearly 106 lakh bales (1 bale $=180 \mathrm{~kg}$ jute) at present (Ray et al. 2015b; Kumar, 2017; MoT, 2018). Production wise West Bengal comes first with $80 \%$ share, followed by 13.4 and
$6 \%$ from Bihar and Assam, respectively. In India, around 7.7 lakh ha lands are under jute cultivation system and nearly $74.5 \%$ of this jute cultivable land is in West Bengal, followed by Bihar and Assam with 15 and $8.6 \%$, respectively. However, there is a noticeable variation in the year-wise area under jute cultivation over past few years (Ray et al. 2012). This fluctuation is governed mainly by three factors like- (a) irregular rainfall during the cultivation time, (b) average price for raw jute received by farmers in the previous year and (c) average price of the competing crops, mainly rice, as received by the farmers in the previous years. Keeping all these variations under consideration, still farmers grow jute every year not only for fibre, but for the sticks which has a well-accepted application for domestic fuel purpose and making farm buildings.

\section{Traditional application of jute}

Jute fibre has some very traditional applications like in hessian, sacking, carpet backing material, yarn etc. (Table 1) (Bag et al. 2016; MoT, 2018). However, application of jute fibre for sacking was very popular and enactment of Jute Packaging 
Table 1: Production (P) and domestic consumption (DC) of traditional jute products (quantities in ‘000' M.T)

\begin{tabular}{ccccccccccc}
\hline \multirow{2}{*}{ Year } & \multicolumn{2}{c}{ Sacking } & \multicolumn{2}{c}{ Hessian } & \multicolumn{3}{c}{ Carpet backing material } & \multicolumn{2}{c}{ Others } & \multicolumn{2}{c}{ Total } \\
\cline { 2 - 11 } & $\mathbf{P}$ & DC & P & DC & P & DC & P & DC & P & DC \\
\hline $2011-12$ & 1165.1 & 1079.1 & 239.9 & 184.2 & 3.6 & 0.1 & 173.8 & 117.9 & 1582.4 & 1381.9 \\
$2012-13$ & 1218.1 & 1118.7 & 210 & 165.8 & 2.9 & 0.8 & 160.3 & 113.9 & 1591.3 & 1399 \\
$2013-14$ & 1150.4 & 1043.1 & 202.5 & 157.6 & 3.3 & 0.4 & 171.5 & 126.4 & 1527.2 & 1327.5 \\
$2014-15$ & 901.8 & 873.2 & 211.3 & 171.7 & 3 & 0.1 & 151.2 & 111.4 & 1267.3 & 1156.2 \\
$2015-16$ & 891.9 & 890.2 & 196.5 & 164.2 & 0 & 0 & 128.9 & 90.2 & 1217.3 & 1144.6 \\
$2016-17$ & 871.6 & 855.9 & 178.6 & 140.9 & 0 & 0 & 92.3 & 78.9 & 1142.5 & 1075.7 \\
$2017-18$ & 824.3 & 805.3 & 158.5 & 130.6 & 0 & 0 & 93.5 & 69.3 & 1076.3 & 1005.2 \\
\hline
\end{tabular}

Source: Ministry of Textiles, GoI.

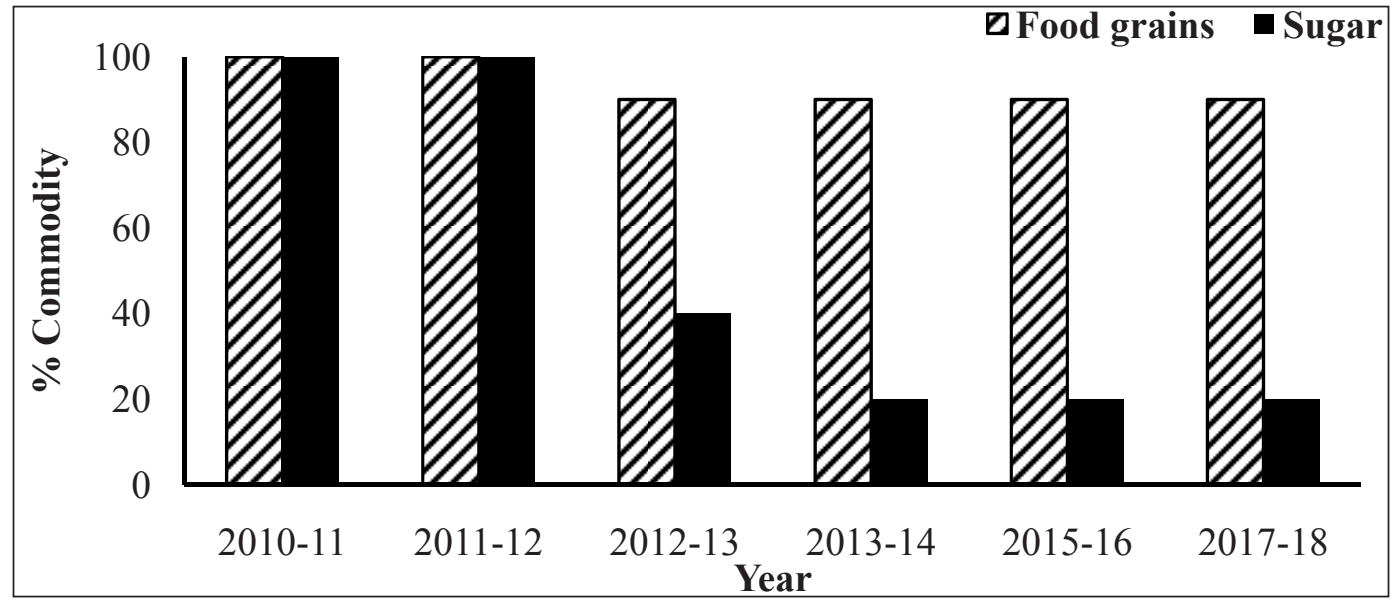

Fig. 1: Changing scenario of usage of jute packing material for food grain and sugar

Material Act (1987) generated huge demand of jute sacking material for packaging of food grains and sugar (Banik and Shil, 2014). Usage of jute of jute packing material were $100 \%$ for food grains and sugars till 2011-12. Thereafter, some relaxations were made and use of jute packing material were reduced to $90 \%$ for food grains till 2017-18. However, the relaxation was huge for sugar. It decreased to $40 \%$ in $2012-13$ and further to $20 \%$ till 2017-18 (Fig. 1). Analysis of data from Table 1 and Fig 1 indicated that there was a significant decrease in production of hessian and sacking during 20112017 which could be influenced by dilution of JPM act. In 20111-12, around 239.9 thousand M.T hessian was produced which decreased by $33.8 \%$ to 158.5 thousand MT by 2017-18. Similarly, there was a sharp decrease $(22.2 \%)$ in production of jute sacking from 1165.1 thousand MT in 2011-12 to from 824.3thousand MT in 2017-18. During this period, total production of jute good decreased from 1582.4 thousand MT of 2011-12 to 1076.3thousand MT in
2017-18. Under such circumstances, future of nearly 40 lakh jute farmers' and 4 lakh mill-workers' have become unpredictable (Goyal, 1990; Kumar, 2017). Hence, there is a need to move in a new direction of application of jute. The diversification of jute has become a necessity not only to survive but also to grow in a new arena.

\section{Jute diversified products}

The diversified application of jute includes light weight carry bags and shopping bags, floor covering, carpet, ornamental fabrics, technical fabrics, home textiles, life style products, geotextiles, agro-textiles, paper, boards, composites etc (Banik and Shil, 2014; Bag et al. 2016). In this context, it is to remember that probably the first jute diversified product was the carpet backing material prepared almost 200 years back. It was exported as the primary and secondary carpet backing material for tufted carpet industries of USA and Europe. However, there is a continuous challenge and 
competition from the artificial 'man made' fibres. Owing to light weight, prolong persistence, customization as per consumers' desire, low cost and spontaneous production, the artificial fibre has generated a tough competition for the natural fibres. But non-biodegradability of artificial fibres in the environment is the biggest drawback of these 'man made' fibres and many developed countries have posed restrictions on the use of artificial fibres/ man made polymer-based products. 'Golden fibre' jute is natural, biodegradable, environment friendly and safe material for use in transport, packing and other services. Thus, the global demand for this 'golden fibre' is increasing every year. But it is interesting to notice that where the traditional use of jute for sacking, hessian etc has a decreasing trend, the export value of jute diversified product shows an increasing trend. In 2012-13, the total export value of jute diversified product was INR 363.6 cores and it increased to INR 590.2 cores in 2016-17. Grossly, the share of jute diversified product in the total jute product exported in 2012-13 was $18 \%$ and it gradually increased to the share of $28 \%$ of the total jute product export in 2016-17. Hence, application of jute for diversified products has opened a new arena for the 'golden fibre' with sustainable future.

\section{Type of jute diversified products}

The jute diversified products can be divided in 2 major categories which are:

(a) Textile products- Jute fabric is prepared from the 'golden fibre' and used for making various products. Jute fibre of various grades can be used to produce various types of fabrics with various designs for diversified products like hand bags and shopping bags, floor covering, carpets, ornamental fabrics, technical textiles, gift items, home textiles, life style products, geotextiles, non-wovens etc. brief details of such products are as follows:

1. Hand bags and shopping bags: Light-weight hand bags and carry bags are very popular and on high demand in this era of consumerism. Thou, plastic bags and artificial fibre bags have huge share, but the disadvantages of plastic and artificial fibre bags have created a global awareness and people want carry bags/ shopping bags from natural fibre. Jute is smartly utilizing this opportunity. A jute bag can be used for 5-6 times and after use it can be composted and utilized as manure. In 2012-13, the export value of jute made carry bags/ shopping bags was nearly INR 169.695 crores. It increased up to $15.5 \%$ by $2016-$ 17 and resulted in export of jute bags \& shopping bags worth INR 322.917 corers. Out of various jute diversified products carry bags and shopping bags are crucial, important and most promising. Table 2 indicated promising and growing market for carry bags and shopping bags.

2. Floor covering: thermal insulation property coupled with eco-friendly nature of this 'golden fibre' has opened up a new market for floor covering. In 2012-13, the export value of floor covering was INR 178.991 crores. It increased to the tune of $12.3 \%$ and figured to be INR 255.108 crores by 2016-17. Various carpets and sataranji from jute are on high demand. Table 3 indicated promising and growing market for floor covering. Fig. 2 showed the demand for floor covering in different countries.

3. Home textiles/ life style products: Generally light weight and colourful products from cotton as well as from synthetic fibres or blended fibres are well known for such items. Jute fibre is course and heavy as compared to these commercial fibres, however recent efforts indicated that fine quality yarn can be prepared from jute fibre. Such fabrics can be

Table 2: Import market projection of hand bags and shopping bags by various countries (in million dollars)

\begin{tabular}{cccccccccc}
\hline Year & UK & USA & Italy & Germany & Australia & Belgium & South Africa & Japan & Chile \\
\hline $2005-06$ & 2 & 3.2 & 1.6 & 1 & 0.4 & 0.2 & 0.1 & 0.2 & 0.1 \\
$2006-07$ & 2 & 2.6 & 1.9 & 0.8 & 0.1 & 0.2 & 0.1 & 0.2 & - \\
$2007-08$ & 14 & 3.4 & 1.2 & 0.6 & 0.3 & 0.3 & 0.1 & 0.2 & - \\
$2008-09$ & 19 & 3.8 & 1.5 & 0.7 & 0.7 & 0.4 & - & 0.2 & - \\
$2009-10$ & 8 & 2.8 & 0.8 & 0.6 & 0.8 & 0.3 & 0.1 & 0.3 & - \\
$2014-15$ & 14 & 4.9 & 1.4 & 0.8 & 1.4 & 0.5 & 0.1 & 0.6 & 0.1 \\
$2019-20^{*}$ & 25 & 8.7 & 2.5 & 1.2 & 2.4 & 0.7 & 0.2 & 1 & 0.1 \\
\hline
\end{tabular}

*expected projection; Source: Ministry of Textiles, GoI. 

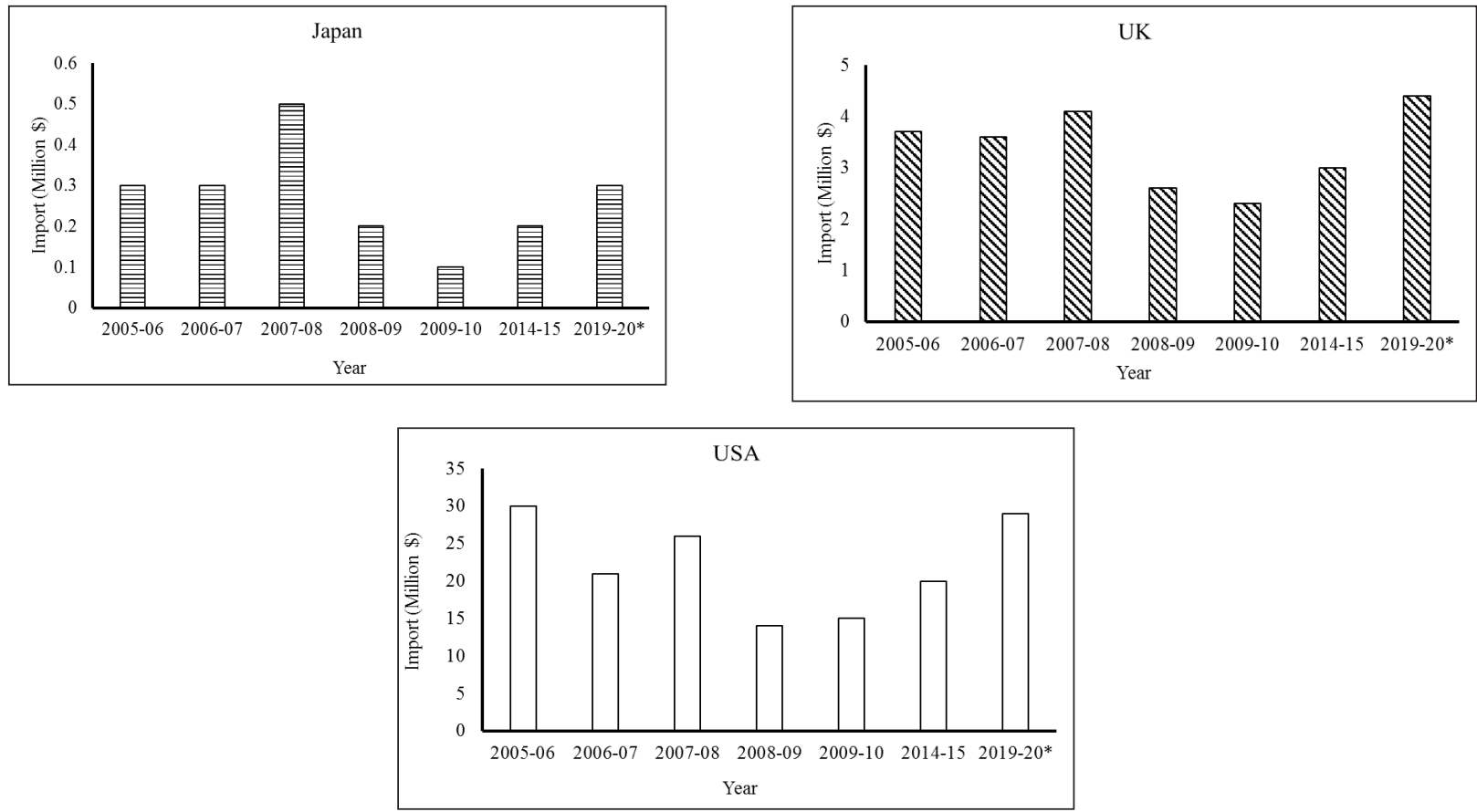

*expected projection; (Source: Ministry of Textiles, GoI)

Fig. 2: Import market projection for floor covering by various countries (in million dollars)

smoothened by selective chemical treatment and coloured as per consumers' requirement. But this area is still under R\&D.

4. School bags/language bag/ ornamental bag: Market for such items is always open and growing. Blended fabric of jute and synthetic fibre could make desirable products. Even waterproof coating and such desired characteristics can be added to the product.

5. Wall hangings/ gift items/ ornamental/ decorative textiles: The 'golden fibre' jute is just suitable for such diversified products. Various designs and colour combinations can produce wonderful items for various customers across the globe. Global market for such items is increasing every year. In 2016-17, the export value for wall hangings, gift items and decorative textiles were nearly INR 0.93, 3.59 and 7.67 crores, respectively.

6. Special/ technical textiles: Special or technical textiles can be prepared form jute fabric by imparting appropriate chemical/ desired treatment. Like heat resistant fabric can be prepared to make gloves and aprons for industrial applications. Even such items for domestic/ household applications can be produced. However, light-weight fabrics will get more popularity.
6. Non-woven textile: Instead of making yarn, the jute fibres get entangled with each other and produce non-woven textiles. Recently, light weight ( 100 gsm) thermal bonded or adhesive bonded nonwoven textiles have fond effective in making light weight carry bags, designer bags or laminating material for various applications. Even non-woven textiles can be used to animal jackets for cold regions.

7. Geo-textiles: Jute as a geo-textile material has huge scope for checking/ restricting soil as well as land degradation. Jute fabrics can be used to stabilize slopes in hills, river banks, road constructions etc. As a geo-textile material jute anchor the soil particle, hold them closely and in due course of time it binds the soils particle and get mixed with the soil. It becomes a part of soil environment and promote vegetation by improving the soil organic matter status.

In road construction, application of jute geo-textiles results in development of less cracks and pot-holes. Therefore, durability of the road gets increased. Along with India, the demand for jute geo-textile in increasing in many countries (Table 3). 
Table 3: Import market projection of geo-textiles by various countries (in million dollars)

\begin{tabular}{ccccc}
\hline Year & USA & UK & Australia & South Africa \\
\hline $2005-06$ & 0.6 & 0.04 & 0.2 & 0.1 \\
$2006-07$ & 1.1 & 0.01 & 0.1 & 0.1 \\
$2007-08$ & 1.4 & 0.03 & 0.2 & 0.2 \\
$2008-09$ & 0.7 & 0.02 & 0.3 & \\
$2009-10$ & 0.3 & 0.01 & 0.3 & 0.1 \\
$2014-15$ & 0.6 & 0.02 & 0.6 & 0.2 \\
$2019-20^{*}$ & 1.1 & 0.03 & 1 & 0.4 \\
\hline
\end{tabular}

*expected projection; (Source: Ministry of Textiles, GoI).

Table 4: Export figure of Indian jute diversified products (in INR crores)

\begin{tabular}{ccccccccc}
\hline Year & $\begin{array}{c}\text { Shopping } \\
\text { bags }\end{array}$ & $\begin{array}{c}\text { Floor } \\
\text { cover }\end{array}$ & $\begin{array}{c}\text { Decorative } \\
\text { textile }\end{array}$ & Gift items & $\begin{array}{c}\text { Wall } \\
\text { hanging }\end{array}$ & $\begin{array}{c}\text { Total jute } \\
\text { diversified product }\end{array}$ & $\begin{array}{c}\text { Total jute } \\
\text { product }\end{array}$ & $\begin{array}{c}\text { \%Share of } \\
\text { JDP }\end{array}$ \\
\hline $2012-13$ & 169.695 & 178.991 & 7.9590 & 6.495 & 0.209 & 363.593 & 1991.802 & 18 \\
$2013-14$ & 244.802 & 216.099 & 18.438 & 3.827 & 0.573 & 483.876 & 2121.949 & 23 \\
$2014-15$ & 251.842 & 238.899 & 12.371 & 4.048 & 0.848 & 508.570 & 1813.810 & 28 \\
$2015-16$ & 322.186 & 222.319 & 10.010 & 6.763 & 0.611 & 562.401 & 1892.344 & 30 \\
$2016-17$ & 322.917 & 255.108 & 7.6700 & 3.590 & 0.930 & 590.215 & 2074.207 & 28 \\
\hline
\end{tabular}

Source: DGCIES, Kolkata.

(b) Non-textile products: For this kind of products any kind of jute fibres, non-suitable for textile items, can be used. Hence, non-textile applications provide a very good opportunity for low graded fibres. The are mainly 2 products which are:

1. Composite board: Jute fibre is used as a reinforcement material and mixed with resigns to prepare composite boards. Depending upon the requirement different types of finishing like waterproof, fire resistant, anti-microbial, anti-insecticidal etc can be imparted. Such composite boards are used for making doors, windows, table tops for domestic or office furniture. Due to deforestation issue, availability of wood for furniture has become a serious constraint across the world. Hence, composite can be used as an alternative of wood.

2. Paper: Jute fibre contains around $60 \%$ cellulose. whereas, the conventional source of paper i.e. wood contains only $40 \%$ cellulose. Therefore, pulp and paper can be prepared from jute fibre. But, due to development and advanced in paper recycling processes, old papers can be recycled at a very low cost. Further, availability of various cellulose rich agro-residue at low cost has put a hurdle for jute fibre in making paper. Because the paper prepared from jute fibre ( INR 30-40 pe kg) will be costlier as the jute fibre is costlier than old papers ( INR 5-10 per $\mathrm{kg}$ ) or agro-residue (INR 2-5 per $\mathrm{kg}$ ). Hand-made paper from jute fibre has its specified customers and the future is promising.

\section{Market for jute diversified products}

Several jute diversified products can be prepared and some important ones have been detailed out. Almost every year, a considerably large amount of jute diversified products is exported to various parts of the world and in return it generates huge revenue for this country (Banik and Shil, 2014; Kumar, 2017). However, 'jute diversified products' means five major products like carry bags and shopping bags, wall hanging, floor covering, gift items and decorative textiles (Table 4). The data predicted a golden future for jute diversified products. The promising markets for jute diversified products are UK, USA, UAE, Saudi Arabia and Turkey. Italy and Germany also have good market opportunities. Table 5 represents market opportunities of various jute diversified products in various countries. 
Table 5: market opportunities of jute diversified products in various countries

\begin{tabular}{ccccc}
\hline \multicolumn{5}{c}{ Market opportunity } \\
\hline Continent & Country & High & Medium & Low \\
\hline North & USA & A, C, D & B & - \\
America & & & & \\
& Canada & A, C & B & - \\
South & Argentina & - & A & - \\
America & & & & \\
& Brazil & - & A, B, C & - \\
& Chile & - & B & - \\
Europe & Peru & - & - & A, B, C \\
& UK & A, C & B & - \\
& Italy & A & - & B, C \\
& Belgium & - & - & A, C \\
& France & - & - & A, B, C, D \\
& Germany & A, B, C & - & - \\
& Spain & - & B & A, C \\
& Netherlands & - & - & C \\
Asia & Saudi Arabia & - & A, B & - \\
& UAE & A, B & C & - \\
& Japan & A, B & - & - \\
Australasia & Australia & A, C & - & B \\
& New & - & - & A, B, C, D \\
& Zealand & & & \\
Africa & South Africa & A, C & - & - \\
& Kenya & - & A & - \\
& Ghana & - & A, B & - \\
& Egypt & - & A & C \\
\hline
\end{tabular}

$A=$ shopping bags; $B=$ Floor cover $C=$ Geo-textiles; $D=$ Wall hanging and others.

\section{CONCLUSION}

Jute fibre is natural, biodegradable and eco-friendly in nature which makes it suitable for packing material. But traditional use of jute as hessian and sacking is facing serious challenges due to reduction in demand as a result of dilution of JPM act. Hence, diversification has become a necessity for sustaining the jute industry. Jute diversified products are gaining importance and the export is rising every year. Grossly, the share of jute diversified product in the total jute products exported in 2012-13 was $18 \%$ and it gradually increased to the share of $28 \%$ of the total jute product export in 2016-17. Jute for diversified products has opened a new arena for the 'golden fibre' with sustainable future.

\section{REFERENCES}

Bag, S.N., Kumar, U.C. and Pal, A.K. 2016. Status and scope of the jute industry in India in comparison to other world producers. Fibres \& Textiles in Eastern Europe, 24(6): 19-25.

Banik, S. and Shil, P. 2014. Indian jute diversified products in the export market, 2000-01 to 2012-13: pattern and performance, International Journal of Economic and Business Review, 2(11): 181-187.

Goyal, H.D. 1990. Indian jute industries- Problems and prospects, Commonwealth Publishers, pp. 239-251.

Kumar, R. 2017. Indian jute industry and its future. International Journal of Business and General Management, 6(4): 21-32.

MoT. 2018. Ministry of Textiles, GoI. http://www.jute.com/ web/guest/market-information/international-marketinformation/potential-market

Ray, D.P., Banerjee, P. and Nag, D. 2015b. Improvement of jute retting processes in India in the context of water scarce situation, International Journal of Bioresource Science, 2(2): 101-110

Ray, D.P., Banerjee, P., Ghosh, R.K. and Nag, D. 2015a. Accelerated Retting of Jute for Economic Fibre Yield, Economic Affairs, 60(4): 693-697.

Ray, D.P., Saha, S.C., Sarkar, A. and Ghosh, R.K. 2016. Production of quality jute fibre through accelerated retting, International Journal of Bioresource Science, 3(2): 57-65.

Ray, K., Neogi, C. and Das, R.C. 2012. Economics of summer paddy-jute substitution: A profile of environmental cost. Asian Journal of Research in Social Science E Humanities, 2(3): 134-150. 